\title{
RELUCTANCE OF PATIENTS WITH DIABETES MELLITUS TO INSULIN THERAPY; PSYCHOLOGICAL INSULIN RESISTANCE
}

\author{
Umair Ali, Muhammad Wajid Munir*, Jahanzeb Maqsood*, Mahwash Jamil**, Syed Saif Ur Rehman*, Abida Mateen Ansari* \\ Combined Military Hospital Abbottabad/National University of Medical Sciences (NUMS) Pakistan, *Al-Nafees Medical College and Hospital, Islamabad \\ Pakistan, ** HITEC Institute of Medical Sciences, Taxilla/National University of Medical Sciences (NUMS) Pakistan
}

\section{ABSTRACT}

Objective: To evaluate factors resulting in reluctance of initiation of insulin therapy in patients with type 2 diabetes mellitus. Study Design: Cross sectional study.

Place and Duration of Study: Medical OPD of a private tertiary care multi-specialty hospital in Islamabad, from Apr to Jul 2019.

Methodology: Patients with diabetes mellitus between age of 30-70 years, who had poor glycaemic control on two oral antidiabetic drugs having $\mathrm{HbA} 1 \mathrm{c}>9 \%$ and were insulin naïve, were included in this study. A validated questionnaire was developed which had two sections; first including the demographic data of the study populations and second having closedended dichotomous questions which were asked from patients by the treating physicians

Results: A total of 180 patients with diabetes mellitus eligible for insulin therapy were included in the study, among them 52 (28.9\%) were agreed to initiate the insulin. Negative attitude and beliefs include painful way of administration $85(66.4 \%)$, difficult insulin storage 98 (76.6\%), risk of hypoglycemia 82 (64.1\%). The mean negative perception Score was 7.35 (SD 0.98).

Conclusion: Psychological insulin resistance is present in significant diabetic population, and it is a big obstacle in insulin therapy initiation and compliance.

Keywords: Compliance, Diabetes mellitus, Hypoglycemia, Insulin, Psychological insulin resistance.

This is an Open Access article distributed under the terms of the Creative Commons Attribution License (http://creativecommons.org/licenses/by/4.0), which permits unrestricted use, distribution, and reproduction in any medium, provided the original work is properly cited.

\section{INTRODUCTION}

During the past 30 years diabetes mellitus has emerged as a global epidemic. Diabetes mellitus alone was directly responsible for an estimated 1.5 million deaths in 2012. World Health Organization projects that diabetes will be the $7^{\text {th }}$ leading cause of death in $2030^{1}$. It has been estimated that there were 285 million people aged 20-79 years throughout the world with diabetes in the year 2010, and this number is projected to increase to 439 million by 2030. Pakistan is ranking at number 7 among countries of high prevalence of Diabetes Mellitus. In 2007, there were 6.9 million patients with diabetes mellitus in Pakistan, which is expected to rise by 11.5 million by 2025 according to the International diabetic foundation 2 .

Due to progressive nature of the disease, in type2 Diabetes Mellitus, oral anti-diabetic therapy often fails to control the glycaemic levels alone and the initiation of insulin therapy becomes an essential approach to achieve the required glycaemic values and ultimately prevent the complications ${ }^{3,4}$. In spite of the proven efficacy of initiation of insulin in any case of type 2 diabetes mellitus it becomes tremendously diffi-

Correspondence: Dr Umair Ali, Asst Comdt (P\&A) Combined Military Hospital, Abbottabad Pakistan

Received: 21 Apr 2020; revised received: 08 Oct 2020; accepted: 16 Oct 2020 cult to do so, in the face of vehement psychological resistance exhibited by the patients 5 . Sometimes, glycaemic control becomes very much at bay because of the patient's resistance to start or intensify insulin therapy ${ }^{6,7}$.

The management of T2DM is quite challenging, however the initiation of insulin therapy at an earlier stage plays a vital role in managing T2DM effectively. For instance, a study reported that insulin therapy was initiated in nearly $25-50 \%$ of T2DM patients in Great Britain within first 6 years of their disease to prevent disease related complications ${ }^{8}$. Despite the importance and promising effects of insulin therapy, insulin initiation is often delayed due to the refusal of insulin therapy by patients with diabetes mellitus, of which, the majority are insulin naïve9.

Psychological insulin resistance is a phenomenon that describes barriers to start insulin therapy ${ }^{10}$. The assessment of knowledge and attitude of patients with diabetes mellitus towards insulin therapy becomes essential because it is postulated that concepts and beliefs towards insulin therapy affect the compliance of therapy and ultimately diabetic control and its complications. The aim of our study is to assess the prevalence of psychological insulin resistance and multiple contributing factors in rather rural area of Islamabad, so that overcoming these factors we can 
make patients with diabetes mellitus to comply with insulin therapy.

\section{METHODOLOGY}

This cross-sectional study was conducted at Department of Medicine in tertiary care multi-specialty hospital in Islamabad, from April to July 2019. Sample size of the study was calculated by precision analysis technique ${ }^{11}$. Patients with diabetes mellitus between age of 30-70 years, who had poor glycaemic control on two oral anti-diabetic drugs having $\mathrm{HbA1c}>9 \%$ and were insulin naïve, were included in this study. Patients who had type 1 DM, psychiatric disease, depression, psychosis, advanced dementia, malignancy, high risk of hypoglycemia and disability with low life expectancy were excluded from the study. A validated questionnaire was developed which had two sections; first including the demographic data of the study populations and second having closed-ended dichotomous questions which were asked from patients by the treating physicians ${ }^{12}$. The patients were advised for insulin therapy for glycaemic control. In patients who refused to start insulin therapy, factors responsible for their refusal were assessed based on their responses to the questionnaire. SPSS-20 was used to analyze data. Descriptive statistics (frequencies and percentages) were used to describe the demographics and extent of insulin reluctance.

\section{RESULTS}

One hundered eighty patients with type 2 diabetes mellitus, who were eligible for insulin therapy after failure of oral antidiabetic drugs, were discussed regarding the initiation of insulin therapy. Only 52 (28.9\%) patients out of 180 agreed to initiate insulin and rest $128(71.1 \%)$ patients showed reluctance to start insulin $(p<0.01)$.

A total of 180 patients, most were female 111 (61.7\%) majority in the age between $40-49$ years i.e.

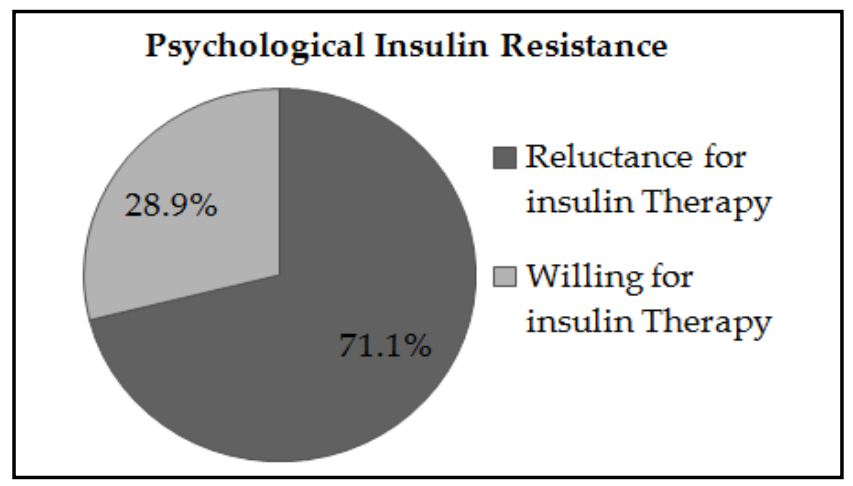

Figure-1: Frequency of psychological insulin resistance $(n=180)$.
$62(34.4 \%)$, between 50-59 years i.e. $73(40.6 \%)$, and $102(56.7 \%)$ patients belong to rural area. Sixty seven $(37.2 \%)$ patients had education upto primary, 82 $(45.6 \%)$ had matric and $31(17.2 \%)$ were graduate or above. Most patients received information from family members or friends 82 (45.6\%) and 104 (57.8\%) having diabetes $>10$ years. Details about demographic characteristics are described in table-I.

Table-I:Demographic characteristics of patients with type 2 diabetes mellitus $(\mathrm{n}=180)$.

\begin{tabular}{l|c}
\hline Variables & $\mathbf{n ~ ( \% )}$ \\
\hline 30 to 39 & $23(12.8 \%)$ \\
\hline 40 to 49 & $62(34.4 \%)$ \\
\hline 50 to 59 & $73(40.6 \%)$ \\
\hline$>60$ & $22(12.2 \%)$ \\
\hline Male & $69(38.3 \%)$ \\
\hline Female & $111(61.7 \%)$ \\
\hline Upto Primary & $67(37.2 \%)$ \\
\hline Matric & $82(45.6 \%)$ \\
\hline Graduation and above & $31(17.2 \%)$ \\
\hline Rural & $102(56.7 \%)$ \\
\hline Urban & $78(43.3 \%)$ \\
\hline Less than 5 & $20(11.1 \%)$ \\
\hline Between 5 to 10 & $56(31.1 \%)$ \\
\hline More than 10 & $104(57.8 \%)$ \\
\hline Family and Friends & $82(45.6 \%)$ \\
\hline Media & $27(15 \%)$ \\
\hline Health care professionals & $71(39.4 \%)$
\end{tabular}

Table-II: Insulin perception Questionnaire Response of patient with diabetes Not Willing for Insulin Therapy ( $\mathrm{n}=128)$.

\begin{tabular}{l|c|c}
\hline Question & Yes, $\mathbf{n}(\%)$ & No, n (\%) \\
\hline $\begin{array}{l}\text { Is insulin more harmful than } \\
\text { oral drugs? }\end{array}$ & $86(67.2)$ & $42(32.8)$ \\
\hline Insulin injection is painful? & $85(66.4)$ & $43(33.6)$ \\
\hline $\begin{array}{l}\text { Insulin therapy is more costly } \\
\text { than drugs? }\end{array}$ & $68(53.1)$ & $60(46.9)$ \\
\hline Insulin storage is difficult? & $98(76.6)$ & $30(23.4)$ \\
\hline $\begin{array}{l}\text { Carrying insulin during } \\
\text { travelling is difficult? }\end{array}$ & $106(82.2)$ & $22(12.2)$ \\
\hline $\begin{array}{l}\text { Insulin therapy is social } \\
\text { stigmata? }\end{array}$ & $72(56.2)$ & $56(43.8)$ \\
\hline $\begin{array}{l}\text { Insulin causes end organ } \\
\text { damage? }\end{array}$ & $105(82)$ & $23(18)$ \\
\hline $\begin{array}{l}\text { Insulin is life time treatment } \\
\text { modality? }\end{array}$ & $88(68.8)$ & $40(31.2)$ \\
\hline $\begin{array}{l}\text { Insulin having dangerous side } \\
\text { effects like hypoglycemia? }\end{array}$ & $82(64.1)$ & $46(35.9)$ \\
\hline $\begin{array}{l}\text { Insulin is the last resort } \\
\text { treatment option? }\end{array}$ & $93(72.7)$ & $35(27.3)$ \\
\hline
\end{tabular}

For 128 patients who were reluctant to start insulin therapy, questionnaire based interview was carried out to look into their beliefs and myths. Negative 
attitudes and beliefs held by majority of the patients eligible for insulin therapy included; insulin is more harmful $86(67.2 \%)$, its way of administration i,e. injection is painful $85(66.4 \%)$, insulin storage and carrying insulin during travelling is much difficult 98 (76.6\%) and $106(82.2 \%)$ respectively. Many patients believe that insulin is the last resort treatment modality 93 $(72.7 \%)$, and can lead to dreadful complications like hypoglycemia $82(64.1 \%)$ and end-organ damage like renal failure $105(82 \%)$.

Negative perception score was calculated based on insulin perception questionnaire. Higher score means more negative perception towards insulin therapy (total score 10). The mean score was 7.35 (SD 0.98) with minimum score 5 and maximum 9 .

\section{DISCUSSION}

Despite the availability of number of oral antidiabetic drugs, insulin therapy has a vital role in the management of diabetes mellitus to prevent its long term complications ${ }^{13,14}$. But in reality utilization of this modality of treatment still has many challenges particularly due to misconception and altered beliefs on the part of patients with diabetes mellitus. In our study significant number of study participants denied to initiate the insulin therapy $(n=128)$. More than $65 \%$ and $51.25 \%$ patients were unwilling to initiate insulin therapy during studies carried out in Rawalpindi and Gujrat, Pakistan respectively ${ }^{14,15}$. Other studies carried out internationally also support the result of this study concluding that $53.29 \%$ patients in Malaysia, more than $50 \%$ in China and $70.6 \%$ in Singapore showed their reluctance for insulin therapy ${ }^{16}$.

In our study, misconceptions that prevailed were the idea that insulin is more harmful, may lead to organ damage and hypoglycemia, is more expensive than oral drugs, injectable way of administration is painful, and is difficult to store as well as handle during travelling. Significant chunk of study population had multiple misconceptions (Negative Perception Score was 7.5).

Charles et al described in a study carried out in Barbados that most participants believe that insulin would cause hypoglycemia, it would give impact that their disease had become worse insulin injections are painful and handling insulin is difficult ${ }^{17}$. Yilmaz et al also described about same misconceptions during a study carried out in Turkey and they found the certain misconceptions in patients with diabetes mellitus regarding insulin that insulin injections are painful, it could lead to hypoglycemia and weight gain and its dependancy ${ }^{18}$. During a study carried out in tertiary care hospital in Gujrat, Pakistan, a sizeable number of patients reported about their concerns regarding self injection, pain of injections and hypoglycemia related to insulin therapy ${ }^{15}$.

Patients with a needle phobia would typically want to avoid medical treatments involving needles. This finding was consistent to patients' avoidance of insulin injection despite their poor glycaemic control. Health care professionals can consider different interventions to overcome needle phobia, such as use of different injection devices or injection sites, and specific counseling to overcome needle phobias.

Eliminating bias, overcoming personal obstacles, and engaging with primary care physicians, trained health professionals, and the first line of a healthcare system, is the modern mode of DM management. Early in such management, patients should be told that insulin may be required at any stage and they need to be educated on insulin use. Such education must explain the significance of insulin, create awareness, and eliminate misunderstandings. Such efforts should counter the obstacles we have described and eliminate the abjection in patients towards taking insulin, observed particularly in patients hailing from developing countries.

\section{CONCLUSION}

Psychological insulin resistance is present in significant diabetic population, and it is a big obstacle in insulin therapy initiation and compliance.

\section{CONFLICT OF INTEREST}

This study has no conflict of interest to be declared by any author.

\section{REFERENCES}

1. Chen DJ, Magliano PZ, Zimmet. The world wide epidemiology of type 2 diabetes mellitus - present and future perspectives: Nat Rev Endocrinol 2011; 8 (4) : 228-36.

2. Khan MU. Lifestyle Modification in the Prevention of Type II Diabetes Mellitus. Oman Med J 2012; 27(2): 170-71.

3. Wong S, Lee J, Ko Y, Chong MF, Lam CK, Tang WE. Perceptions of insulin therapy amongst Asian patients with diabetes in Singapore. Diabetic Med 2011; 28(2): 206-11.

4. Porcellati F, Lin J, Lucidi P, Bolli GB, Fanelli CG. Impact of patient and treatment characteristics on glycemic control and hypoglycemia in patients with type 2 diabetes initiated to insulin glargine or NPH: A post hoc, pooled, patient-level analysis of 6 randomized controlled trials. Medicine 2017; 96(5): e6022.

5. Khunti K, Millar-Jones D. Clinical inertia to insulin initiation and intensification in the UK: a focused literature review. Primary care diabetes. 2017; 11(1): 3-12.

6. Polonsky WH, Henry RR. Poor medication adherence in type 2 diabetes: recognizing the scope of the problem and its key contributors. Patient Pref Adher 2016; 10(1): 1299-307. 
7. Luk A. Psychological insulin resistance: scope of the problem. Hong Kong Med J 2016; 22(4): 304-05.

8. Saleem A, Masood I, Khan TM. Insulin perception among insulin-naïve type-2 diabetes mellitus patients in Pakistan. Cogent Med 2016; 3(1): 1229374.

9. Tan WL, Asahar SF, Harun NL. Insulin therapy refusal among type II diabetes mellitus patients in KubangPasu district, Kedah, Malaysia. Singapore Med J 2015; 56(4): 224.

10. Luk A. Psychological insulin resistance: scope of the problem. Hong Kong Med J 2016; 22(4): 304-5.

11. Malterud K, Siersma VD, Guassora AD. Sample size in qualitative interview studies: guided by information power. Qual Health Res 2016; 26(13): 1753-60.

12. Taherdoost H. Validity and reliability of the research instrument; how to test the validation of a questionnaire/survey in a research. Int J Acad Res 2016; 5(3): 2294-1747.

13. Khan H, Lasker SS, Chowdhury TA. Prevalence and reasons for insulin refusal in Bangladeshi patients with poorly controlled
Type 2 diabetes in East London. Diabet Med 2008; 25(9): 1108-11.

14. Khan MM, Manzoor S, Kahlid MA, Tarrar MG, Aslam F, Ahmad SI. Factors responsible for delay in initiation of insulin treatment in type-2 diabetes mellitus patients with secondary failure of oral hypoglycemic agents. J Rawal Med Coll 2016; 20(4): 244-50.

15. Khan H, Lasker SS, Chowdhury TA. Prevalence and reasons for insulin refusal in Bangladeshi patients with poorly controlled Type 2 diabetes in East London. Diabet Med 2008; 25(9): 1108-11.

16. Zulkarnain AK, Tahir A. Psychological insulin resistance (PIR) among type 2 diabetes patients at public health clinics in federal territory of Malaysia. Med J Malaysia 2011; 10(2): 1-5.

17. Aylor CG, Taylor G, Atherley A. The Barbados Insulin Matters (BIM) study: Barriers to insu-lin therapy among a populationbased sample of people with type 2 diabetes in the Caribbean island of Barbados. J Clini Tran-slat Endocrinol 2017; 8: 49-53.

18. Yilmaz A, Ak M, Cim A, Palanci Y, Kilinc F. Factors influencing insulin usage among type 2 diabetes mellitus patients: A study in Turkish primary care. Eur J General Pract 2016; 22(4): 255-61. 